\title{
A Comparative Study on Safety and Efficacy of Caudal, Thoracic Epidural and Intra Venous Analgesia in Paediatric Cardiac Surgery: A Double Blind Randomised Trial
}

\section{-Safety and Efficacy of Regional Anesthesia in Pediatric Cardiac Surgeries}

\author{
Mahesh Vakamudi ${ }^{1}$, Rajesh Kumar V. Kodali ${ }^{*}$, Ranjith B. Karthekeyan ${ }^{2}$, Periyasamy Thangavel ${ }^{3}$, \\ Kamalakannan G. Sambandham²

\begin{abstract}
${ }^{1}$ Department of Anaesthesiology, Sri Ramachandra Institute of Higher Education and Research (SRIHER), Chennai, India ${ }^{2}$ Department of Cardiac Anaesthesiology, Sri Ramachandra Institute of Higher Education and Research (SRIHER), Chennai, India ${ }^{3}$ HOD Department of Cardiac Surgery, Sri Ramachandra Institute of Higher Education and Research (SRIHER), Chennai, India Email: ${ }^{*}$ rajesh.kodali@gmail.com
\end{abstract}

How to cite this paper: Vakamudi, M., Kodali, R.K.V., Karthekeyan, R.B., Thangavel, P. and Sambandham, K.G. (2020) A Comparative Study on Safety and Efficacy of Caudal, Thoracic Epidural and Intra Venous Analgesia in Paediatric Cardiac Surgery: A Double Blind Randomised Trial-Safety and Efficacy of Regional Anesthesia in Pediatric Cardiac Surgeries. World Journal of Cardiovascular Surgery, 10, 101-114. https://doi.org/10.4236/wjcs.2020.107013

Received: June 2, 2020

Accepted: July 4, 2020

Published: July 7, 2020

Copyright $\odot 2020$ by author(s) and Scientific Research Publishing Inc. This work is licensed under the Creative Commons Attribution International License (CC BY 4.0).

http://creativecommons.org/licenses/by/4.0/

(c) (i) Open Access

\section{Abstract}

Introduction: Regional anaesthesia combined with general anaesthesia reduces stress response to surgery, duration of ventilation, intensive care unit (ICU) stay and promotes early recovery. Studies on thoracic epidural, caudal analgesia along with general anaesthesia (GA) in paediatric cardiac surgery are limited hence we aimed to compare efficacy and safety of caudal, thoracic epidural and intravenous analgesia in paediatric cardiac surgery. Methodology: This study was conducted in the Department of Anaesthesiology in a tertiary care teaching hospital in southern India from February 2019 to December 2019. 90 children were randomised into group A, group B, group C. Children in group A received caudal analgesia along with GA. Group B children received thoracic epidural along with GA. Group $C$ patients received intravenous analgesia along with GA. Rescue analgesia $1 \mathrm{mcg} / \mathrm{kg}$ fentanyl given in all 3 groups if pain score is more than 4. Primary outcome assessed was post-op pain scores. Secondary outcome assessed was duration of ventilation, duration of intensive care unit stay. Results: All patients were comparable in terms of age, sex, weight, mean RACHS score, baseline heart rate and blood pressure. Pain scores were significantly lower in thoracic epidural group compared to other two groups. Duration of ventilation was lower in thoracic epidural group (91.17 \pm 43.85) minutes and caudal (199.6 \pm 723.59$)$ minutes compared to intravenous

${ }^{*}$ Corresponding author. 
analgesia groups $(436.37 \pm 705.51)$ minutes. Duration of ICU stay was significantly low in thoracic epidural group $(2.73 \pm 0.69)$ days compared to caudal $(3.7 \pm 2.8)$ and intravenous analgesia groups $(4.33 \pm 0.920)$. We didn't have any complications like hematoma, transient or permanent neurological sequelae in regional anesthesia groups. Conclusion: Regional anaesthesia along with general anaesthesia was more effective in pain relief than intravenous analgesia with general anaesthesia in paediatric cardiac surgery.

\section{Keywords}

Caudal Analgesia, Thoracic Epidural Analgesia, Pain Scores, Paediatric Cardiac Surgery

\section{Introduction}

Pain during surgery and in post-operative period was of more concern in paediatric patients. Regional anaesthesia combined with general anaesthesia was more popular method nowadays especially in non-cardiac surgeries. Regional anaesthesia provides many advantages to patients by providing analgesia, attenuation of stress response, reduction in morbidity and mortality [1]. Despite of these advantages practice of regional anaesthesia in paediatric cardiac surgery was limited due to major believes like epidural hematoma and hemodynamic disturbances. As per available literature incidence of hematoma and hemodynamic disturbances were minimal due to paediatric regional anaesthesia [2] [3] [4] [5]. Inadequate pain relief during intra operative and post-operative period contribute to metabolic (proteolysis, hyperglycaemia), neuroendocrine (increase in serum cortisol and catecholamine levels), immunological (inhibition of $\mathrm{NK}$ cell and $\mathrm{T}$ helper cell function) and haematological changes (post-operative hyper coagulable state) [6]. These changes can be minimized by administering a combination of regional anaesthesia and general anaesthesia, thereby provide adequate pain relief and decreases the duration of ventilation and stay in intensive care unit [5] [7] [8] [9].

Although few studies were available on comparison of caudal analgesia and non-caudal analgesia groups, combined with general anesthesia in paediatric cardiac surgical patients, but comparative studies of thoracic epidural with caudal and intravenous analgesia were limited in our population [5] [10] [11] [12]. Hence we aimed to compare the efficacy of regional anaesthesia with intravenous analgesia in terms of pain scores in children undergoing cardiac surgery as a primary outcome.

Duration of ventilation and stay in intensive care unit (ICU) were also compared between 3 groups as secondary outcome.

\section{Materials and Methods}

Setting: This study was conducted in the Department of Anaesthesiology in a 
tertiary care teaching hospital in southern India from February 2019 to December 2019.

This study was approved by the Institutional Ethical Committee (IEC//18/ DEC/145/54) and Clinical Trial Registry of India (CTRI) (CTRI/2019/02/017575).

Design: A double blinded randomised control design was employed to compare the efficacy of thoracicepidural, caudal and intravenous analgesia in pain relief during intraoperative and postoperative period.

Recruitment of the Subjects: Children were recruited after obtaining written, informed consent from parents/guardians. Children aged from six months to seven years, weighing from 5 - $12 \mathrm{~kg}$ with RACHS (Risk adjustment in congenital heart surgery) score 1 - 3 undergoing elective cardiac surgery were included in the study. Children who had coagulopathies, local skin infections, spinal cord anomalies, pre-existing neurological illness and failed regional analgesic techniques were excluded from the study. Ninety children were randomised into three groups $\mathrm{A}, \mathrm{B}$, and $\mathrm{C}$ by a computer generated block randomisation technique (Figure 1). Parents of children and anaesthesiologist who was collecting the data in intensive care unit were blinded to the allotment of the group. All the children were anaesthetised by same anaesthesiologist as per standard department protocol and he was not involved in post-operative follow up. Children in group A had received caudal analgesia with $1.6 \mathrm{ml} / \mathrm{kg}$ of solution containing

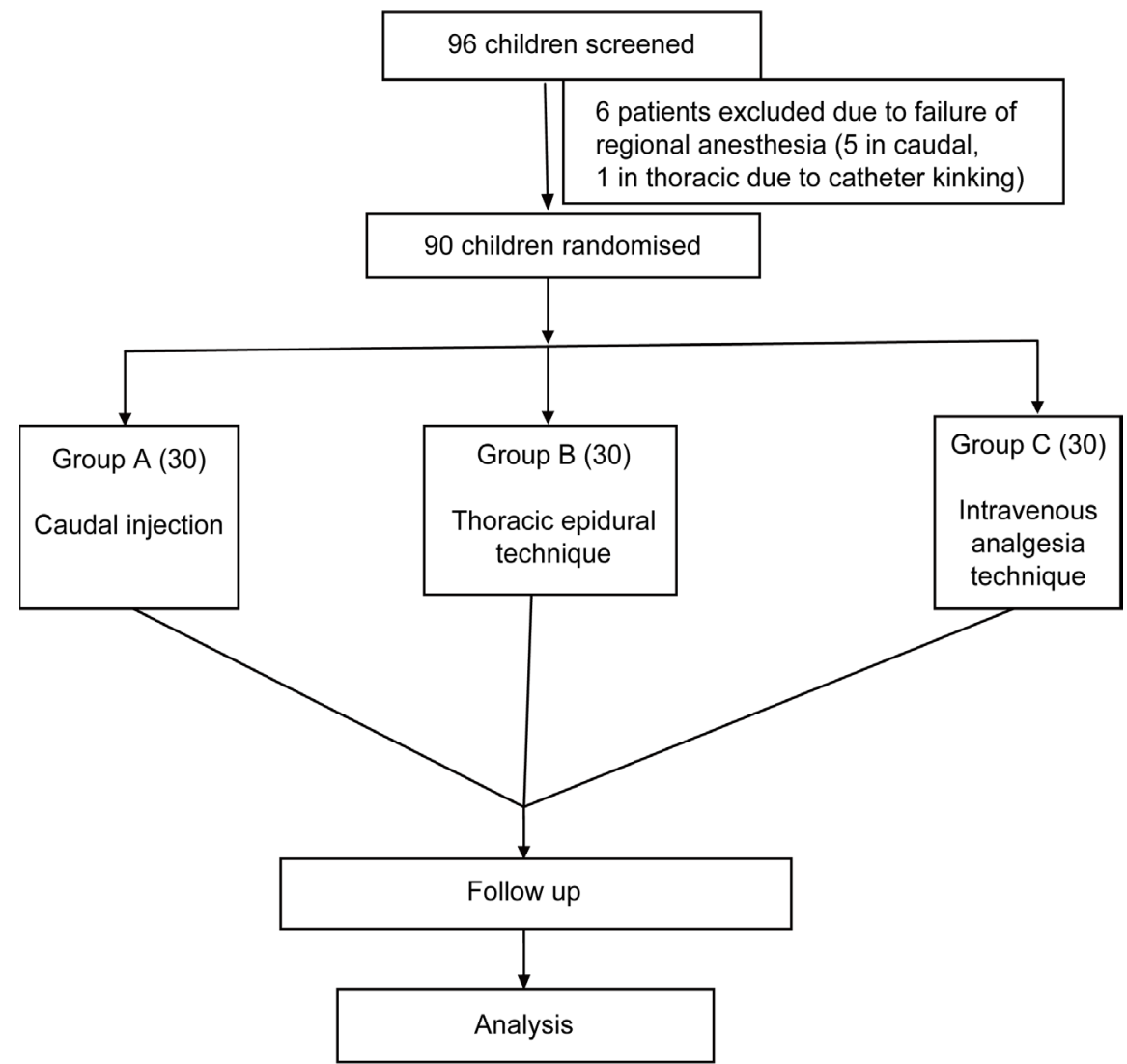

Figure 1. Consort flow chart. 
bupivacaine $2 \mathrm{mg} / \mathrm{kg}$ with Morphine 50 micrograms $(\mathrm{mcg}) / \mathrm{kg}$ after general anaesthesia with endotracheal intubation and controlled mechanical ventilation [13]. Children in group B received thoracic epidural at T5-T8 space with $20 \mathrm{~g}$ epidural needle containing $24 \mathrm{~g}$ epidural catheter (B Braun). A bolus dose containing $0.5 \mathrm{ml} / \mathrm{kg}$ of $0.25 \%$ bupivacaine was given. After 15 minutes of bolus dose, maintenance dose of $0.2-0.3 \mathrm{ml} / \mathrm{kg} / \mathrm{hr}$ was given with a solution containing $0.125 \%$ bupivacaine, $3 \mathrm{mcgs} / \mathrm{ml}$ fentanyl additive throughout the procedure and in post-operative period up for $12 \mathrm{hrs}$. Children in group $\mathrm{C}$ received intravenous fentanyl boluses at a dose of $2 \mathrm{mcg} / \mathrm{kg} / \mathrm{hr}$ throughout procedure and 1 $\mathrm{mcg} / \mathrm{kg} \mathrm{hr}$ infusion as maintenance for $12 \mathrm{hrs}$ of post-operative period. Any hypotension after procedure was treated with ephedrine, phenylephrine or intravenous fluid boluses depending on underlying heart condition to maintain balance between systemic and pulmonary vascular resistance. All patients received intravenous heparin $4 \mathrm{mg} / \mathrm{kg} 1$ hour post intervention [14] [15]. Initiation of cardiopulmonary bypass ( $\mathrm{CPB})$, conduct and weaning of $\mathrm{CPB}$, reversal of heparin with protamine were done according to standard department protocol. Heart Rate (HR), Mean arterial blood Pressure (MAP), Central Venous Pressure (CVP) were monitored. Vasoactive inotropic scores (VIS) were assessed for all the patients before shifting to ICU. Post op pain scores were assessed with FLACC scale (Face, Leg, Activity, Cry, Consolability) every hourly for $12 \mathrm{hrs}$ after shifting to ICU. If pain score was more than 4 rescue analgesia of intravenous fentanyl $1 \mathrm{mcg} / \mathrm{kg}$ was given. Reassessment of pain was done after 5 - 10 minutes. If pain score continued to be more than 4 intravenous fentanyl $1 \mathrm{mcg} / \mathrm{kg}$ was repeated. Duration of mechanical ventilation andduration of ICU stay was noted. Primary outcome assessed was post-operative pain scores. Secondary outcome assessed was duration of ventilation and duration of stay in intensive care unit. Serum cortisol and blood glucose levels were assessed four times- $1^{\text {st }}$ post induction and before intervention, $2^{\text {nd }}$ while on $\mathrm{CPB}, 3^{\text {rd }}$ at $6 \mathrm{hrs}$ post intervention and $4^{\text {th }}$ at $12 \mathrm{hrs}$ post intervention. Vasoactive inotropic scores and other complications like epidural/sub cutaneous hematoma were also compared between three groups. Vasoactive inotropic score was calculated by formula of dopamine dose $\mu \mathrm{g} \cdot \mathrm{kg}^{-1} \mathrm{~min}^{-1}+$ dobutamine dose $\mu \mathrm{g} \cdot \mathrm{kg}^{-1} \mathrm{~min}^{-1}+100 \times$ epinephrine dose $\mu \mathrm{g} \cdot \mathrm{kg}^{-1} \mathrm{~min}^{-1}+100 \times$ nor epinephrine dose $\mu \mathrm{g} \cdot \mathrm{kg}^{-1} \mathrm{~min}^{-1}+10 \times$ Milrinone dose $\mu \mathrm{g} \cdot \mathrm{kg}^{-1} \mathrm{~min}^{-1}+10,000 \times$ vasopressin dose units $\cdot \mathrm{kg}^{-1} \mathrm{~min}^{-1}$.

Sample size was estimated based on a previous study done by Samantaray DJ et al.-with power of $90 \%$ and alpha error of 5\% (standard deviation of 1.2 in Group 1, standard deviation of 1.7 in group 2 with mean difference of 2.1, effect size of 1.37, 2 sided) [11]. This establishes sample size of 18 in each group but we have included 30 in each group.

Statistical analysis: Statically package for the social sciences (SPSS) 16.0 software was used for statically analysis. Chi square test was performed to assess the significance of association between categorical variables. ANOVA, and repeated measures of ANOVA tests were performed along with post hoc analysis using bonferroni correction. 


\section{Results}

All the three groups were comparable in terms of age, sex, weight, cardiopulmonary bypass time, surgical time and mean RACHS score (Table 1). Baseline heart rate and mean arterial pressures were comparable between three groups. We observed significantly lower pain scores at $2 \mathrm{hrs}, 4 \mathrm{hrs}, 6 \mathrm{hrs}$ of post-operative period in group A $(1.67,1.68,2.61$ respectively) and group B (1.53, 1.33, 2.33 respectively) when compared to group $\mathrm{C}(3.93,3.98,4.92)$. Post hoc analysis by Bonferroni correction shows significant difference in pain scores at $2 \mathrm{hrs}, 4 \mathrm{hrs}$ and 6 hrs between group A and group $C(P=0.001)$. There was significant difference in pain scores at $2 \mathrm{hrs}, 4 \mathrm{hrs}, 6 \mathrm{hrs}$ post intervention between group B and group $C(P=0.001)$. There was no significant difference at $2 \mathrm{hrs}, 4 \mathrm{hrs}$ and 6 hrs between group A and group B (Table 2).

Pain scores at $12 \mathrm{hrs}$ was significantly lower in group B $(2.57 \pm 1.81)$ when compared to group A $(4.27 \pm 1.72)$ and group $C(6.03 \pm 1.18)$. Post hoc analysis by Bonferroni correction shows significant difference in pain scores at $12 \mathrm{hrs}$ between group $A$ and group $B(P=0.001)$, group $A$ and group $C(P=0.001)$ and group $B$ and group $C(P=0.001)$.

Post op duration of ventilation was significantly lower in group B when compared to two other groups (Table 3). Post hoc analysis of duration of ventilation shows statistically significant difference between group B $(91.17+/-43.85 \mathrm{mi}-$ nutes) and group $C(436.3+/-705.51$ minutes) with a $P$ value of 0.02 . There was no significant difference observed between group A $(199.6+/-723.59)$ when compared to group B $(91.17+/-43.85)$ and group A $(199.6+/-723.59)$ when compared to group C $(436.3+/-705.51)$.

Duration of ICU stay during post-operative period was significantly lower in group B when compared to other two groups (Table 3). Post hoc analysis of duration of ICU stay shows statistically significant difference between group $\mathrm{B}$ $(2.73+/-0.69)$ days compared to group $\mathrm{C}(4.33+/-0.92)$ with a $\mathrm{P}$ value of 0.03 . There was no significant difference observed between group A $(3.70+/-2.87)$ when compared to group B $(2.73+/-0.69)$ and between group A $(3.70+/-2.87)$ when compared to group $\mathrm{C}(4.33+/-0.92)$.

Table 1. Patient demographic data comparison between 3 groups.

\begin{tabular}{ccccc}
\hline & Group A & Group B & Group C & P value \\
\hline Age in years & $2.61 \pm 1.14$ & $2.92 \pm 1.43$ & $3.16 \pm 0.97$ & 0.94 \\
Sex (male: female) & $18: 12$ & $20: 10$ & $17: 13$ & 0.65 \\
Weight in kgs & $9.38 \pm 1.90$ & $10.29 \pm 1.45$ & $9.45 \pm 1.97$ & 0.88 \\
Bypass time in minutes & $87.97 \pm 26.75$ & $83.20 \pm 13.21$ & $88.77 \pm 18.09$ & 0.51 \\
Surgical duration & $182.56 \pm 24.58$ & $188 \pm 18.83$ & $179 \pm 25.23$ & 0.46 \\
Mean RACHS score & $2.13 \pm 0.66$ & $1.96 \pm 0.61$ & $2.06 \pm 0.58$ & 0.68 \\
\hline
\end{tabular}


Table 2. Pain score comparison between three groups.

\begin{tabular}{|c|c|c|c|c|c|}
\hline $\begin{array}{l}\text { Pain score } \\
\text { comparison }\end{array}$ & Group A & Group B & Group C & $\begin{array}{l}\mathrm{P} \text { value between } \\
\text { groups }\end{array}$ & $\begin{array}{c}\text { Cumulative } \\
\text { P value }\end{array}$ \\
\hline At $2 \mathrm{hrs}$ in post op icu & $1.67 \pm 0.79$ & $1.53 \pm 0.70$ & $3.93 \pm 0.94$ & $\begin{array}{c}0.20^{\star} \\
0.001 \dagger \\
0.001 \ddagger\end{array}$ & 0.001 \\
\hline At $4 \mathrm{hrs}$ in post op icu & $1.68 \pm 0.76$ & $1.33 \pm 0.96$ & $3.98 \pm 0.88$ & $\begin{array}{c}0.38^{\star} \\
0.001 \dagger \\
0.001 \ddagger\end{array}$ & 0.001 \\
\hline At $6 \mathrm{hrs}$ in post op icu & $2.61 \pm 1.56$ & $2.33 \pm 0.96$ & $4.92 \pm 0.98$ & $\begin{array}{c}0.07^{\star} \\
0.001 \dagger \\
0.001 \ddagger\end{array}$ & 0.001 \\
\hline At $12 \mathrm{hrs}$ in post op icu & $4.27 \pm 1.72$ & $2.57 \pm 1.81$ & $6.03 \pm 1.18$ & $\begin{array}{c}0.01^{\star} \\
0.001 \dagger \\
0.001 \ddagger\end{array}$ & 0.001 \\
\hline
\end{tabular}

${ }^{*}$ Level of significance between group A and group B; $\nmid$ Level of significance between group A and group C; $\ddagger$ Level of significance between group B and group C; $P$ value less than 0.05 considered to be significant.

Table 3. Post-operative data comparison between three groups.

\begin{tabular}{|c|c|c|c|c|c|}
\hline & Group A & Group B & Group C & $\begin{array}{l}\text { P value between } \\
\text { groups }\end{array}$ & $\begin{array}{c}\text { Cumulative } \\
\text { P value }\end{array}$ \\
\hline $\begin{array}{c}\text { Duration of ventilation in } \\
\text { minutes }\end{array}$ & $199.6 \pm 723.59$ & $91.17 \pm 43.85$ & $436.37 \pm 705.51$ & $\begin{array}{c}0.80^{\star} \\
0.36 \dagger \\
0.026 \ddagger\end{array}$ & 0.03 \\
\hline $\begin{array}{l}\text { Duration of icu } \\
\text { stay in days }\end{array}$ & $3.7 \pm 2.8$ & $2.73 \pm 0.69$ & $4.33 \pm 0.92$ & $\begin{array}{l}0.11^{\star} \\
0.52 \dagger \\
0.03 \ddagger\end{array}$ & 0.003 \\
\hline VIS score & $8.47 \pm 4.65$ & $5.50 \pm 2.57$ & $9.57 \pm 3.89$ & $\begin{array}{c}0.01^{*} \\
0.70 \dagger \\
0.001 \ddagger\end{array}$ & 0.001 \\
\hline $\begin{array}{l}\text { Rescue analgesia (fentanyl) } \\
\text { requirement in mcgs }\end{array}$ & $22.6 \pm 15.42$ & $7.50 \pm 7.39$ & $75.83 \pm 13.83$ & $\begin{array}{l}0.001^{*} \\
0.001 \dagger \\
0.001 \ddagger\end{array}$ & 0.001 \\
\hline
\end{tabular}

${ }^{*}$ Level of significance between group A and group B; †Level of significance between group A and group C; $\ddagger$ Level of significance between group B and group C; $P$ value less than 0.05 considered to be significant.

Post op rescue analgesia (fentanyl) requirement was significantly lower in group B when compared to other two groups (Table 3 ). Post hoc analysis shows significant difference between group B $(7.5+/-7.3) \mathrm{mcgs}$ when compared to group A $(22.6+/-15.42)$ with a $\mathrm{P}$ value of 0.001 , group $\mathrm{B}(7.5+/-7.3)$ when compared to group C $(75.8+/-13.8)$ with a $\mathrm{P}$ value of 0.001 , and group A (22.6 +/- 15.42) when compared to group $C(75.8+/-13.8)$ with a $P$ value of 0.001 .

Vasoactive inotropic score immediately after shifting to ICU was significantly low in group B when compared to other two groups (Table 3). Post hoc analysis shows statistically significant difference between group A $(8.47+/-4.65)$ and group B $(5.5+/-2.57)$ with a $\mathrm{P}$ value of 0.01 . Significant difference was observed between group B $(5.5+/-2.57)$ and group C $(9.57+/-3.89)$ with a $P$ value of 
0.001 but no difference was observed between group A $(8.47+/-4.65)$ and group C (9.57+/- 3.89).

We also compared stress response (serum cortisol levels, blood glucose level) between threegroups. In all the groups serum cortisol level increased from baseline to $12 \mathrm{hrs}$ after intervention ( $\mathrm{df} 3.73, \mathrm{~F}=71.07, \mathrm{P}$ value 0.001 ) but rise in serum cortisol levels were significantly lower in groups $\mathrm{A}$ and $\mathrm{B}$ compared to group C (Table 4). In all the three groups blood glucose levels increased from baseline to $12 \mathrm{hrs}$ post intervention, but rise in blood glucose levels was more in group $\mathrm{C}$ when compared to group A and group B (Table 5).

Heart rate in group B was low when compared to other two groups at skin incision, $2 \mathrm{hrs}, 4 \mathrm{hrs}, 6 \mathrm{hrs}$, and $12 \mathrm{hrs}$ after shifting to ICU (Table 6). There was significant difference in heart rate within the groups from base line to $12 \mathrm{hrs}$ (df $7.84, \mathrm{~F}=31.93$, $\mathrm{P}$ value 0.001 ). Post hoc analysis by Bonferroni test between the groups shows significant difference between group $\mathrm{A}$ and group $\mathrm{B}$ with a $\mathrm{P}$ value of 0.001 , between group $\mathrm{A}$ and group $\mathrm{C}$ with a $\mathrm{P}$ value of 0.001 and between group $\mathrm{B}$ and group $\mathrm{C}$ with a $\mathrm{P}$ value 0.001 . Mean artery pressure was comparable in all 3 groups from baseline to $12 \mathrm{hrs}$ after shifting to ICU (Table 7). No epidural hematoma was observed in regional anaesthesia groups. Six children were reintubated due to diaphragmatic palsy.

Table 4. Serum cortisol level comparison between three groups.

\begin{tabular}{|c|c|c|c|c|c|}
\hline $\begin{array}{l}\text { Serum Cortisol levels in } \mu \mathrm{g} / \mathrm{dl} \\
\qquad(\text { mean }+/-\mathrm{sd})\end{array}$ & $\begin{array}{l}\text { Group A } \\
\text { (Caudal) }\end{array}$ & $\begin{array}{c}\text { Group B } \\
\text { (Thoracic epidural) }\end{array}$ & $\begin{array}{c}\text { Group C } \\
\text { (Intravenous } \\
\text { analgesia) }\end{array}$ & $\begin{array}{l}\mathrm{P} \text { value with in } \\
\text { groups from base } \\
\text { line to } 12 \mathrm{hrs}\end{array}$ & $\begin{array}{l}P \text { value between } \\
\text { the groups }\end{array}$ \\
\hline Baseline & $24.47(6.09)$ & $24.43(6.90)$ & $24.73(10.68)$ & \multirow{4}{*}{0.001} & ${ }^{\star} 0.230$ \\
\hline On CPB & $40.17(13.21)$ & $32.03(12.91)$ & $60.63(29.24)$ & & $\dagger 0.001$ \\
\hline $6 \mathrm{hrs}$ after intervention & $51.03(21.36)$ & $38.90(19.56)$ & $75.71(27.87)$ & & \multirow[b]{2}{*}{$\ddagger 0.001$} \\
\hline $12 \mathrm{hrs}$ after intervention & $61.17(33.49)$ & $44.20(34.34)$ & $89.13(43.20)$ & & \\
\hline
\end{tabular}

${ }^{*}$ Level of significance between group A and group B; $†$ Level of significance between group A and group C; $¥$ Level of significance between group B and group C; $P$ value less than 0.05 considered to be significant.

Table 5. Blood glucose level comparison between three groups.

\begin{tabular}{|c|c|c|c|c|c|}
\hline $\begin{array}{l}\text { Blood glucose level in } \mathrm{mg} / \mathrm{dl} \\
\qquad(\text { mean } \pm \mathrm{sd})\end{array}$ & Group A & Group B & Group C & $\begin{array}{l}\mathrm{P} \text { value with in } \\
\text { groups from base } \\
\text { line to } 12 \mathrm{hrs}\end{array}$ & $\begin{array}{l}\mathrm{P} \text { value between } \\
\text { the groups }\end{array}$ \\
\hline Base line & $103.03 \pm 9.41$ & $97.03 \pm 13.90$ & $102.77 \pm 17.13$ & \multirow{4}{*}{0.001} & ${ }^{\star} 0.06$ \\
\hline On CPB & $145.87 \pm 19.03$ & $131.20 \pm 25.86$ & $173.57 \pm 53.53$ & & $\dagger 0.04$ \\
\hline $6 \mathrm{hrs}$ after intervention & $156.07 \pm 35.21$ & $136.30 \pm 32.55$ & $203.47 \pm 62.03$ & & \multirow{2}{*}{$\ddagger 0.001$} \\
\hline $12 \mathrm{hrs}$ after intervention & $177.70 \pm 55.19$ & $144.97 \pm 40.01$ & $211.43 \pm 76.01$ & & \\
\hline
\end{tabular}

${ }^{\star}$ Level of significance between group A and group B; †Level of significance between group A and group C; $¥$ Level of significance between group B and group C; ${ }^{*} \mathrm{P}$ value less than 0.05 considered to be significant. 
Table 6. Heart rate comparison between three groups.

\begin{tabular}{|c|c|c|c|c|c|}
\hline $\begin{array}{c}\text { Heart rate } \\
(\text { mean }+/- \text { sd })\end{array}$ & Group A & Group B & Group C & $\begin{array}{l}\mathrm{P} \text { value with in } \\
\text { groups from base } \\
\text { line to } 12 \mathrm{hrs}\end{array}$ & $\begin{array}{l}\text { P value between } \\
\text { the groups }\end{array}$ \\
\hline Baseline & $124.83 \pm 9.63$ & $124.33 \pm 10.21$ & $124.73 \pm 8.66$ & \multirow{6}{*}{0.001} & \multirow[b]{2}{*}{${ }^{\star} 0.001$} \\
\hline Skin incision & $126.27 \pm 12.31$ & $115.03 \pm 14.26$ & $137.33 \pm 8.41$ & & \\
\hline $2 \mathrm{hrs}$ after shifting to icu & $133.33 \pm 9.14$ & $120.43 \pm 13.63$ & $141.90 \pm 4.96$ & & \multirow[b]{2}{*}{$\dagger 0.001$} \\
\hline $4 \mathrm{hrs}$ after shifting to icu & $135.93 \pm 7.72$ & $121.10 \pm 8.98$ & $142.80 \pm 4.21$ & & \\
\hline $6 \mathrm{hrs}$ after shifting to icu & $140.73 \pm 10.53$ & $120.63 \pm 8.33$ & $144.70 \pm 5.63$ & & \multirow[b]{2}{*}{$\ddagger 0.001$} \\
\hline $12 \mathrm{hrs}$ after shifting to icu & $141.47 \pm 10.27$ & $120.77 \pm 9.11$ & $147.47 \pm 6.74$ & & \\
\hline
\end{tabular}

${ }^{\star}$ Level of significance between group A and group B; †Level of significance between group A and group C; $¥$ Level of significance between group B and group C; $P$ value less than 0.05 considered to be significant.

Table 7. Mean arterial pressure comparison between three groups.

\begin{tabular}{|c|c|c|c|c|c|}
\hline $\begin{array}{l}\text { Mean artery pressure in } \\
\mathrm{mm} \text { of } \mathrm{Hg}(\text { mean }+/-\mathrm{sd})\end{array}$ & Group A & Group B & Group C & $\begin{array}{l}\mathrm{P} \text { value Within the } \\
\text { groups from baseline } \\
\text { to } 12 \mathrm{hrs} \text { after } \\
\text { shifting to icu }\end{array}$ & $\begin{array}{l}\mathrm{P} \text { value between } \\
\text { the groups }\end{array}$ \\
\hline Baseline & $53.90 \pm 8.51$ & $52.53 \pm 5.60$ & $53.53 \pm 6.18$ & \multirow{9}{*}{0.065} & \multirow{3}{*}{${ }^{\star} 1.00$} \\
\hline & & & & & \\
\hline Skin incision & $51.30 \pm 6.22$ & $52.03 \pm 6.21$ & $54.23 \pm 6.81$ & & \\
\hline \multirow{2}{*}{$2 \mathrm{hrs}$ after shifting to icu } & $52.37 \pm 5.33$ & $54.97 \pm 5.61$ & $54.13 \pm 6.43$ & & \multirow{3}{*}{$\dagger 1.00$} \\
\hline & & & & & \\
\hline $4 \mathrm{hrs}$ after shifting to icu & $56.47 \pm 6.51$ & $57.43 \pm 4.60$ & $54.47 \pm 5.90$ & & \\
\hline \multirow[t]{2}{*}{$6 \mathrm{hrs}$ after shifting to icu } & $55.43 \pm 5.96$ & $55.90 \pm 7.04$ & $53.47 \pm 5.37$ & & \multirow{3}{*}{$\ddagger 0.524$} \\
\hline & & & & & \\
\hline $12 \mathrm{hrs}$ after shifting to icu & $54.53 \pm 6.25$ & $55.31 \pm 5.30$ & $52.27 \pm 7.28$ & & \\
\hline
\end{tabular}

${ }^{*}$ Level of significance between group A and group B; †Level of significance between group A and group C; $¥$ Level of significance between group B and group C; $P$ value less than 0.05 considered to be significant.

\section{Discussion}

In this study all the groups were comparable in terms of age, sex, weight, mean $\mathrm{CPB}$ time, mean surgical time and mean RACHS score and different types of surgeries (Table 8). Baseline serum cortisol, blood glucose levels, heart rate, mean arterial blood pressures were also comparable between three groups. Post-operative pain scores were lower in caudal analgesia group during post-operative period in our study similar to previous studies done by Abd-Elshafy et al. [16], Samantaray et al. [11], Nasr and Abdel Hamid et al. [17]. In contrast, study done by Nguyen et al. reported no significant difference in post-operative pain scores and opioid consumption between caudal and non-caudal groups [10]. This can be attributed to lower dose of $1 \mathrm{ml} / \mathrm{kg}$ of $0.125 \%$ bupivacaine in caudal analgesia which may not sufficient to provide prolonged post-operative analgesia. Mean post-operative 
pain scores up to six hours were lower in caudal analgesia group similar to a study by Rosen et al. and they were comparable with thoracic epidural analgesia [18]. But at 12 hrs post-operative pain scores were significantly higher in caudal group compared to thoracic epidural group (Figure 2). Although caudal analgesia did not provide total pain relief, overall opioid consumption was lesser than control group. Thoracic epidural analgesia provided good analgesia in post-operative period with very minimal rescue opioid consumption in our study, similar to study done by Vila et al. [12]. Peterson et al. in 2000 retrospectively reviewed the data of children receiving regional anaesthesia for cardiac surgery and found that $89 \%$ children are extubated in operating room, 95\% children had pain score less than 4 at all intervals in post-operative period and the rate of adverse effects were lower in thoracic catheter epidural approach as compared with caudal, lumbar epidural, spinal approaches [5].

Table 8. Sub group analysis of various surgeries in 3 groups.

\begin{tabular}{ccccccc}
\hline Type of surgery & Caudal & & Thoracic epidural & \multicolumn{2}{c}{ Intravenous analgesia } \\
\hline ASD & 5 & ASD & 6 & ASD & 4 \\
VSD & 8 & VSD & 9 & PAPVC repair & 1 \\
TOF & 4 & GLENN & 4 & VSD & 6 \\
Partial AVSD & 1 & TOF & 3 & TOF & 6 \\
Glenn & 3 & Mitral valve repair & 1 & GLENN & 4 \\
Fontan & 5 & Partial AVSD & 2 & Partial AV canal & 3 \\
PA banding & 1 & BT shunt & 3 & Fontan & 4 \\
BT shunt & 3 & Fontan & 2 & BT shunt & 1 \\
& & & & Rastelli & 1 \\
\hline
\end{tabular}

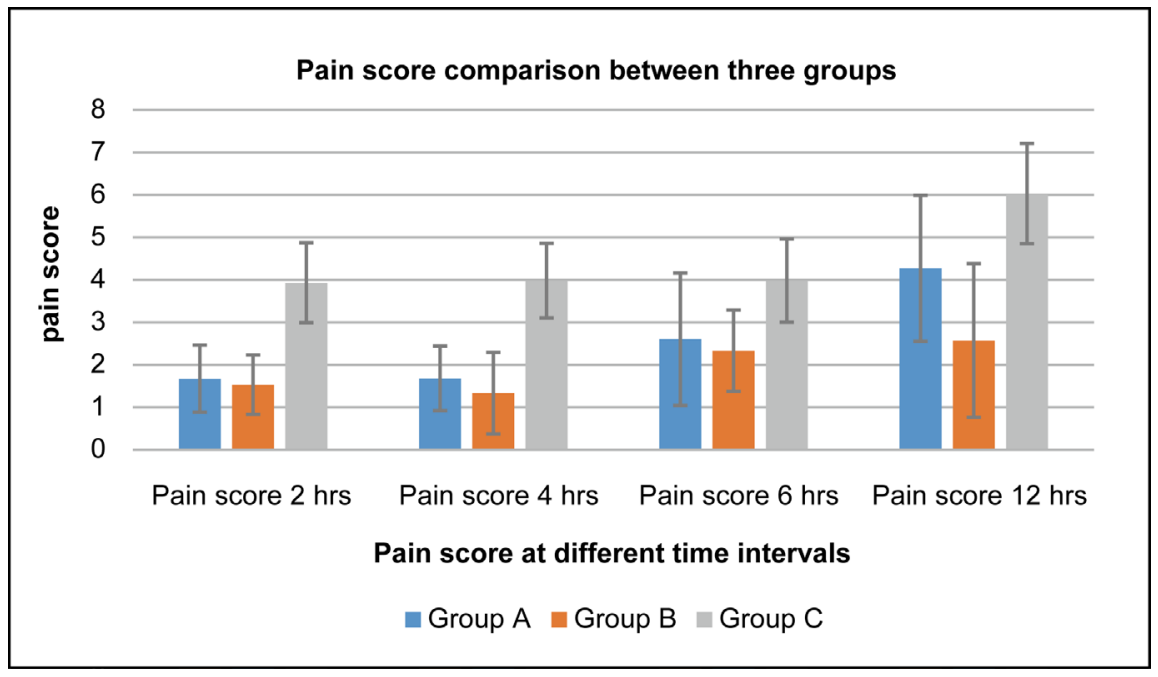

Figure 2. Pain score comparison between three groups. 
In our study, duration of ventilation was lower in thoracic epidural group compared to other two groups. In a study by Mittancht et al. caudal morphine 50 $100 \mathrm{mcg} / \mathrm{kg}$ or intrathecal morphine $5-10 \mathrm{mcg} / \mathrm{kg}$ was given during procedure, $79 \%$ of cases were extubated in operating room [19]. But in our study prolonged ventilation in caudal analgesia group could be attributed to need for elective observation for hemodynamic stability for 1 hour in ICU, and diaphragmatic palsy in three patients secondary to phrenic nerve injury. Although duration of ventilation was lower in thoracic epidural analgesia group compared to caudal analgesia, but this difference was stastically not significant (Figure 3).

Duration of stay in ICU was similar in caudal and intravenous analgesia groups, whereas thoracic epidural group had significantly lesser stay in ICU compared to intravenous analgesia group [20] (Figure 4). Although duration of ICU stay was lower in thoracic epidural analgesia group compared to caudal analgesia but this difference was statistically not significant. In contrast to our findings a study by Sayedkaoud Abd-elshafy reported that single dose of caudal $\left(0.125 \% 1.5 \mathrm{ml} \cdot \mathrm{kg}^{-1}\right.$ bupivacaine plus neostigmine $2 \mathrm{mcg} \cdot \mathrm{kg}^{-1}$ ) provided optimal conditions of early extubation had lesser duration of ICU stay [16]. Similar to a study by Makhija et al., serum Cortisol levels on CPB, and in post-operative period were significantly lower in caudal group compared to intravenous analgesia group [21]. Study by Nasr and Abdelhamid reported increase in serum cortisol in caudal analgesia groups but the increase was significantly low in dexmeditomodine and bupivacaine group compared to fentanyl and bupivacaine group [17]. Duncan et al. conducted a study on 40 children less than 4 years undergoing elective paediatric cardiac surgery with one of five doses of fentanyl ranging from $2 \mu \mathrm{g} \cdot \mathrm{kg}^{-1}$ to $25,50,100$, $150 \mu \mathrm{g} \cdot \mathrm{kg}^{-1}$. Patients in $2 \mu \mathrm{g} \cdot \mathrm{kg}^{-1}$ group had significant rise in pre bypass glucose, pre and post bypass serum cortisol levels pre and post bypass nor epinephrine levels compared to other 4 doses, fentanyl doses of 25 and $50 \mu \mathrm{g} \cdot \mathrm{kg}^{-1}$ sufficient enough to reduce stress response in paediatric patient undergoing heart surgery [22].

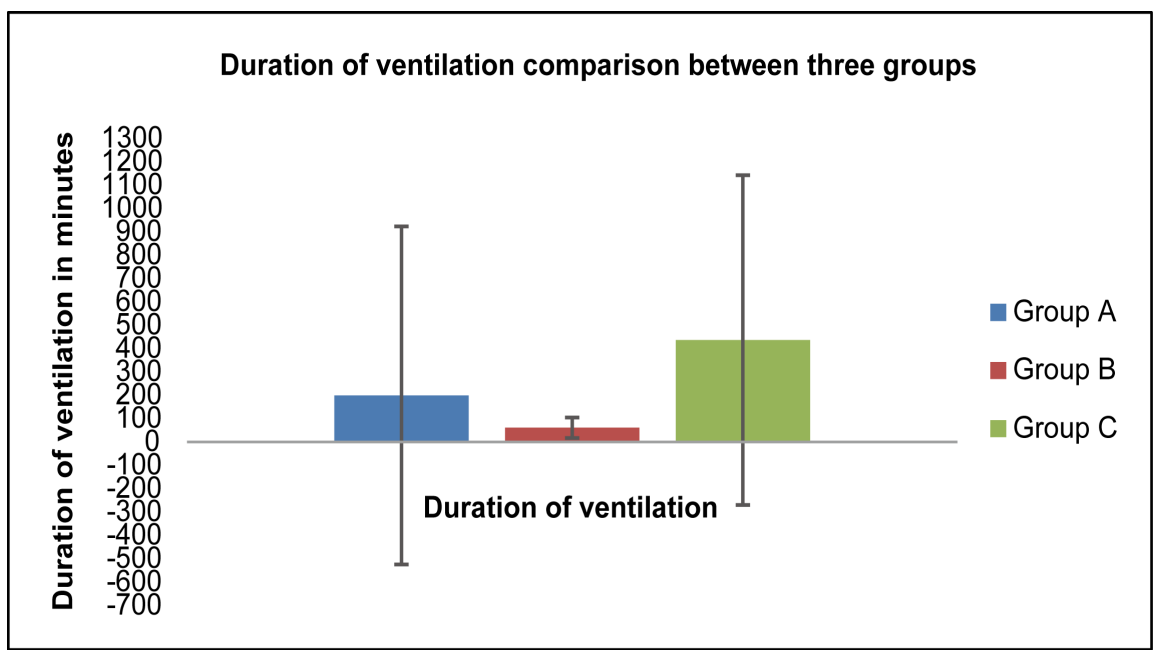

Figure 3. Duration of ventilation comparison between three groups. 


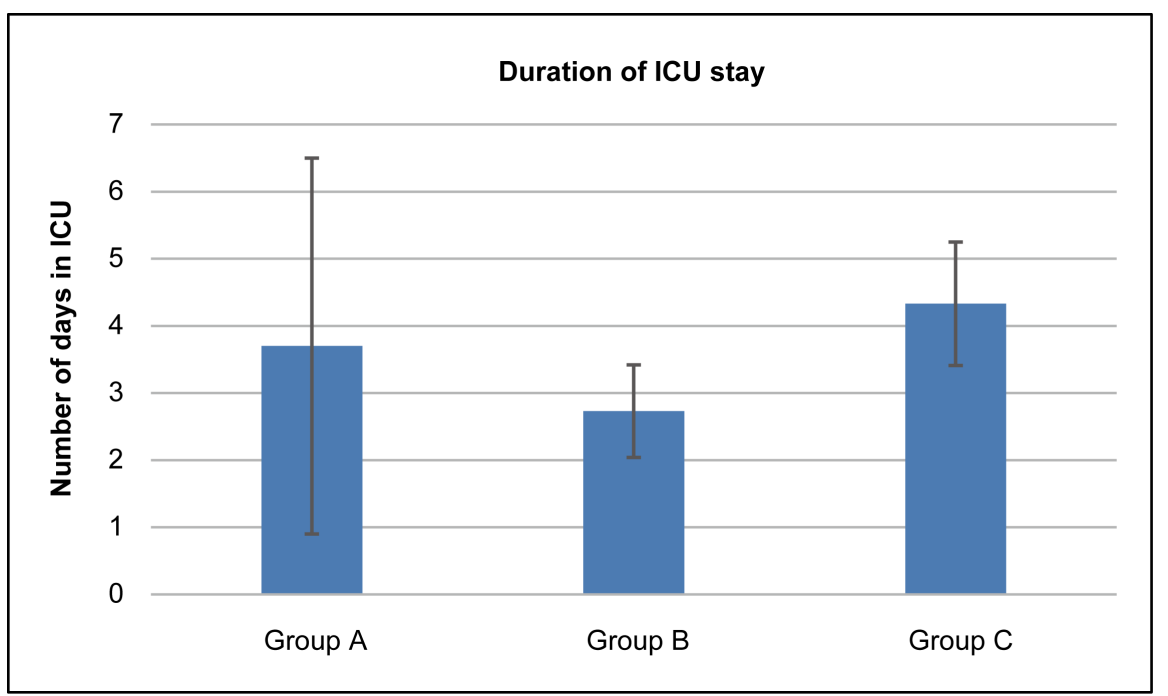

Figure 4. Duration of ICU stay comparison between three groups.

Similar to the above study we also had raised serum cortisol and blood glucose levels in intravenous analgesia group. Blood glucose levels are significantly low on $\mathrm{CPB}$ in thoracic epidural and caudal groups compared to intravenous analgesia group [21] similar to a study done by Makhija et al., Mean vasoactive inotropic scores immediately after shifting to ICU were significantly lower in thoracic epidural group, compared to two other groups. There was no significant difference in vasoactive inotropic score between caudal and intra venous analgesia groups. We haven't observed any epidural hematoma in caudal and thoracic epidural group. No episodes of nausea and vomiting was observed in any of the groups. Mean heart rate from skin incision to $12 \mathrm{hrs}$ after shifting to ICU was significantly low in thoracic epidural group compared to other two groups and heart rate was significantly low in caudal group compared to intra venous analgesia group. Mean arterial pressures are comparable in all three groups from baseline to $12 \mathrm{hrs}$ after shifting to ICU. Most common complication reported in a study done by Suresh S, Benjamin J Walker in paediatric regional anaesthesia was block failure $(1 \%-4 \%)$ secondary to catheter dislodgement, occlusion, disconnection [4] [23]. In our study we had 5 patients of caudal analgesia and 1 patient in thoracic epidural due to catheter kinking, were excluded due to failed regional anaesthesia (Figure 1). Incidence of other complications like epidural hematoma of $0-3.5$ per 10,000, permanent neurological sequelae of $0-0.4$ per 10,000, transient neurologic deficit of 2.4 in 10,000, local anaesthetic systemic toxicity of 0.76 per 10,000, epidural abscess 0.76 per 10,000 , cutaneous infections $0.5 \%$ were reported in previous studies [4] [24]. We didn't had any complications like epidural hematoma, transient or permanent neurologic sequelae in our study, as our sample is smaller when compared to a study by Suresh S, Benjamin J Walker. American Society of Regional Anaesthesia (ASRA) guidelines in 2018 mentioned that incidence of epidural hematoma in patients undergoing heparinisation after CPB as 1 in 4583, but this was mathematical assumption. This may be due to under reporting of 
complications like epidural hematoma [15]. In study by Peterson et al. mentioned that lowest complication rate was observed in thoracic epidural catheter approach compared to other methods [5]. This was secondary to short catheter threading distance compared to other epidurals and there by reduction in venous disruption. Other reasons were selective segmental anesthesia at site of surgical incision, no lower extremity motor blockade which permits early post-operative assessment of motor function. We reintubated 6 children 3 in caudal and 3 in intravenous group. 5 children were reintubated secondary to diaphragmatic palsy, 1 child was intubated secondary to hemodynamic instability due to arrhythmia.

\section{Limitations}

We haven't excluded patients who had reintubation, which in turn would have affected duration of ventilation and ICU stay. VIS scores were measured only once that was after shifting to ICU. We couldn't record aorta clamp time as most of atrial septal defects were done under fibrillatory arrest. We are not able to standardise the surgeon for intraoperative procedures like sternotomy and pericardiotomy.

\section{Conclusion}

Patients in regional anaesthesia groups had lesser pain scores when compared to intravenous analgesia group. Thoracic epidural group had lesser duration of mechanical ventilation and lesser duration of ICU stay compared to caudal and intravenous group. Thoracic epidural and caudal blocks can be given safely by experienced anaesthesiologists in paediatric cardiac surgery with RACHS score less than 3.

\section{Conflicts of Interest}

The authors declare no conflicts of interest regarding the publication of this paper.

\section{References}

[1] Hammer, G.B. (1999) Regional Anesthesia for Pediatric Cardiac Surgery. Journal of Cardiothoracic and Vascular Anesthesia, 13, 210-213. https://doi.org/10.1016/S1053-0770(99)90091-5

[2] Roberts, S. (2018) Regional Anesthesia in Pediatric Patients: General Considerations. NYSORA.

[3] Rao, T.L. and El-Etr, A.A. (1981) Anticoagulation Following Placement of Epidural and Subarachnoid Catheters: An Evaluation of Neurologic Sequelae. Anesthesiology, 55, 618-620. https://doi.org/10.1097/00000542-198155060-00002

[4] Walker, B.J., Long, J.B., Sathyamoorthy, M., Wright, C. and Rosenbloom, J. (2018) Complications in Pediatric Regional Anesthesia: An Analysis of More than 100,000 Blocks from the Pediatric Regional Anesthesia Network. Anesthesiology, 129, 721-732. https://doi.org/10.1097/ALN.0000000000002372

[5] Peterson, K.L., DeCampli, W.M., Pike, N.A., Robbins, R.C. and Reitz, B.A. (2000) A 
Report of Two Hundred Twenty Cases of Regional Anesthesia in Pediatric Cardiac Surgery. Anesthesia \& Analgesia, 90, 1014.

https://doi.org/10.1097/00000539-200005000-00002

[6] Iwasaki, M., Edmondson, M., Sakamoto, A. and Ma, D. (2015) Anesthesia, Surgical Stress, and "Long-Term" Outcomes. Acta Anaesthesiologica Taiwanica, 53, 99-104. https://doi.org/10.1016/j.aat.2015.07.002

[7] Novak-Jankovič, V. and Paver-Eržen, V. (2002) How Can Anesthetists Modify Stress Response during Perioperative Period? In: Gullo, A., Ed., Anaesthesia, Pain, Intensive Care and Emergency Medicine, Springer, Milan, 1025-1034. https://doi.org/10.1007/978-88-470-2099-3_89

[8] Hammer, G.B., Ngo, K. and Macario, A. (2000) A Retrospective Examination of Regional plus General Anesthesia in Children Undergoing Open Heart Surgery. Anesthesia \& Analgesia, 90, 1020-1024. https://doi.org/10.1097/00000539-200005000-00004

[9] De Pinto, M., Dagal, A., O’Donnell, B., Stogicza, A., Chiu, S. and Edwards, W.T. (2015) Regional Anesthesia for Management of Acute Pain in the Intensive Care Unit. International Journal of Critical Illness and Injury Science, 5, 138-143. https://doi.org/10.4103/2229-5151.164917

[10] Nguyen, K.N., Byrd, H.S. and Tan, J.M. (2016) Caudal Analgesia and Cardiothoracic Surgery: A Look at Postoperative Pain Scores in a Pediatric Population. Paediatric Anaesthesia, 26, 1060-1063. https://doi.org/10.1111/pan.12990

[11] Samantaray, D.J., Trehan, M., Chowdhry, V. and Reedy, S. (2019) Comparison of Hemodynamic Response and Postoperative Pain Score between General Anaesthesia with Intravenous Analgesia versus General Anesthesia with Caudal Analgesia in Pediatric Patients Undergoing Open-Heart Surgery. Annals of Cardiac Anaesthesia, 22, 35. https://doi.org/10.4103/aca.ACA_215_17

[12] Vilà, R., Potau, N., Garcia, M., Acosta, D. and Miguel, E. (2000) Thoracic Epidural Anaesthesia in Paediatric Open Cardiac Surgery. Our Experience with Ropivacaine-Morphine. European Journal of Anaesthesiology, 17, 150. https://doi.org/10.1097/00003643-200000002-00490

[13] Sharma, V.K. (2013) Is Caudal Dexmedetomidine in Pediatric Cardiac Surgery a Novel Idea? Annals of Cardiac Anaesthesia, 16, 115-116.

[14] Baker, J.E. and Mazer, C.D. (2008) Anticoagulation and Regional Anesthesia in Cardiac Surgery: Safety Considerations. Techniques in Regional Anesthesia and Pain Management, 12, 17-25. https://doi.org/10.1053/j.trap.2007.10.003

[15] Horlocker, T.T., Vandermeuelen, E., Kopp, S.L., Gogarten, W., Leffert, L.R. and Benzon, H.T. (2018) Regional Anesthesia in the Patient Receiving Antithrombotic or Thrombolytic Therapy: American Society of Regional Anesthesia and Pain Medicine Evidence-Based Guidelines (Fourth Edition). Regional Anesthesia \& Pain Medicine, 43, 263-309. https://doi.org/10.1097/AAP.0000000000000763

[16] Abd-Elshafy, S.K., Abdalla, E., Ali, M. and Mohamed, H. (2015) Caudal Neostigmine and Bupivacaine Facilitates Early Extubation and Provides Prolonged Postoperative Analgesia in Children Undergoing Open Heart Surgery. Anesthesia and Clinical Research, 6, 1-6.

[17] Nasr, D.A. and Abdelhamid, H.M. (2013) The Efficacy of Caudal Dexmedetomidine on Stress Response and Postoperative Pain in Pediatric Cardiac Surgery. Annals of Cardiac Anaesthesia, 16, 109. https://doi.org/10.4103/0971-9784.109744

[18] Rosen, K.R. and Rosen, D.A. (1989) Caudal Epidural Morphine for Control of Pain Following Open Heart Surgery in Children. Anesthesiology, 70, 418-421. https://doi.org/10.1097/00000542-198903000-00009 
[19] Mittnacht, A.J.C., Thanjan, M., Srivastava, S., Joashi, U., Bodian, C., Hossain, S., et al. (2008) Extubation in the Operating Room after Congenital Heart Surgery in Children. The Journal of Thoracic and Cardiovascular Surgery, 136, 88-93. https://doi.org/10.1016/j.jtcvs.2007.11.042

[20] Leyvi, G., Taylor, D.G., Reith, E., Stock, A., Crooke, G. and Wasnick, J.D. (2005) Caudal Anesthesia in Pediatric Cardiac Surgery: Does It Affect Outcome? Journal of Cardiothoracic and Vascular Anesthesia, 19, 734-738.

https://doi.org/10.1053/j.jvca.2005.01.041

[21] Makhija, N., Kiran, U., Choudhary, S., Lakshmy, R., Das, S. and Sendasgupta, C. (2009) Caudal Epidural Sufentanil and Bupivacaine Decreases Stress Response in Paediatric Cardiac Surgery. Annals of Cardiac Anaesthesia, 12, 27. https://doi.org/10.4103/0971-9784.45010

[22] Duncan, H.P., Cloote, A., Weir, P.M., Jenkins, I., Murphy, P.J., Pawade, A.K., et al. (2000) Reducing Stress Responses in the Pre-Bypass Phase of Open Heart Surgery in Infants and Young Children: A Comparison of Different Fentanyl Doses. British Journal of Anaesthesia, 84, 556-564. https://doi.org/10.1093/bja/84.5.556

[23] Suresh, S., Long, J., Birmingham, P.K. and De Oliveira, G.S. (2015) Are Caudal Blocks for Pain Control Safe in Children? An Analysis of 18,650 Caudal Blocks from the Pediatric Regional Anesthesia Network (PRAN) Database. Anesthesia \& Analgesia, 120, 151-156. https://doi.org/10.1213/ANE.0000000000000446

[24] Rosen, D.A., Rosen, K.R. and Hammer, G.B. (2002) Pro: Regional Anesthesia Is an Important Component of the Anesthetic Technique for Pediatric Patients Undergoing Cardiac Surgical Procedures. Journal of Cardiothoracic and Vascular Anesthesia, 16, 374-378. https://doi.org/10.1053/jcan.2002.124152 